\title{
Signal Transduction by Tumor Necrosis Factor Mediated by JNK Protein Kinases
}

\author{
HAYLA K. SLUSS, ${ }^{1}$ TAMERA BARRETT, ${ }^{1,2}$ BENOIT DÉRIJARD, ${ }^{1,2}$ AND ROGER J. DAVIS ${ }^{1,2 *}$ \\ Program in Molecular Medicine, Department of Biochemistry and Molecular Biology, University of Massachusetts \\ Medical School, ${ }^{1}$ and Howard Hughes Medical Institute, ${ }^{2}$ Worcester, Massachusetts 01605
}

Received 22 April 1994/Returned for modification 1 June 1994/Accepted 25 August 1994

\begin{abstract}
JNK protein kinases are distantly related to mitogen-activated protein kinases (ERKs) and are activated by dual phosphorylation on Tyr and Thr. The JNK protein kinase group includes the 46-kDa isoform JNK1. Here we describe the molecular cloning of a second member of the JNK group, the 55-kDa protein kinase JNK2. The activities of both JNK isoforms are markedly increased by exposure of cells to UV radiation. Furthermore, JNK protein kinase activation is observed in cells treated with tumor necrosis factor. Although both JNK isoforms phosphorylate the $\mathrm{NH}_{2}$-terminal activation domain of the transcription factor c-Jun, the activity of JNK2 was approximately 10-fold greater than that of JNK1. This difference in c-Jun phosphorylation correlates with increased binding of c-Jun to JNK2 compared with JNK1. The distinct in vitro biochemical properties of these JNK isoforms suggest that they may have different functions in vivo. Evidence in favor of this hypothesis was obtained from the observation that JNK1, but not JNK2, complements a defect in the expression of the mitogen-activated protein kinase HOG1 in the yeast Saccharomyces cerevisiae. Together, these data indicate a role for the JNK group of protein kinases in the signal transduction pathway initiated by proinflammatory cytokines and $\mathrm{UV}$ radiation.
\end{abstract}

Tumor necrosis factor alpha (TNF- $\alpha$ ) was discovered as a factor in the serum of mice injected with bacillus CalmetteGuérin (Mycobacterium bovis BCG) or lipopolysaccharide that induced tumor necrosis in tumor-bearing mice (16). A similar factor, TNF- $\beta$ (lymphotoxin), was discovered as a soluble factor released from the lymph node $T$ cells of immunized rats that shows cytolytic activity toward murine L929 fibroblasts (59). Subsequent studies have led to the molecular cloning of the two related factors, TNF- $\alpha$ and TNF- $\beta$, that have similar actions in vivo and in vitro (26). These TNFs are potent cytokines that elicit a large number of biological effects, including hemorrhagic necrosis of transplanted tumors, cytotoxicity, immunoregulation, cellular proliferation, antiviral responses, and transcriptional activation of many genes $(9,24$, 26). In particular, TNF- $\alpha$ has an important role in the inflammatory response and is a principal mediator of toxic shock and sepsis.

The primary source of TNF- $\alpha$ is the activated macrophage or monocyte, while activated $\mathrm{T}$ cells represent the major source of TNF- $\beta$. Although these factors are released from different cell types, both TNF- $\alpha$ and TNF- $\beta$ bind to the same two cell surface receptors $(55$ and $75 \mathrm{kDa}$ ) that are widely expressed in the tissues of the body (70). The extracellular domains of these receptors share $28 \%$ homology and are divided into four repeating Cys-rich domains, similar to the low-affinity nerve growth factor receptor, Fas antigen, CD40, OX40, and CD27 (68). In contrast, the cytoplasmic domains of the two TNF receptors have no obvious homology to each other (70). This has led to some controversy about the role of each receptor $(34,72)$. However, a consensus view is that the $55-\mathrm{kDa}$ receptor mediates cytotoxicity, antiviral activity, fibroblast proliferation, and transcription factor activation $(13,21,22,47$, $68-70,72,73,76,77)$. The $75-\mathrm{kDa}$ receptor may mediate a distinct signaling role $(35,42)$. Alternatively, the $75-\mathrm{kDa}$

\footnotetext{
* Corresponding author.
}

receptor may act as a coreceptor that presents TNF for binding the 55-kDa signaling receptor (71).

The structure of TNF bound to the $55-\mathrm{kDa}$ receptor has been determined by X-ray crystallography to consist of three receptor molecules bound symmetrically to one TNF- $\beta$ trimer (8). This structure suggests that TNF-induced aggregation of the $55-\mathrm{kDa}$ receptor may represent an initial step in the signal transduction mechanism. Interestingly, ligand-induced aggregation has been established to account for the activation of tyrosine kinase receptors (60). Receptor aggregation may therefore be a common mechanism of activation of several classes of cell surface receptors.

The mechanism of signal transduction by TNF receptors is poorly understood. However, it is likely that the TNF signaling mechanism is similar to that of the proinflammatory cytokine interleukin-1 (IL-1). Both of these cytokines cause marked activation of transcription factors AP-1 and NF-кB $(14,46,51)$. In addition, the analysis of cellular phosphoproteins by twodimensional gel electrophoresis demonstrates that TNF and IL-1 cause increased phosphorylation of a common group of at least 53 proteins and decreased phosphorylation of 10 additional proteins (31). Treatment of cells with other cytokines does not regulate the phosphorylation of the same group of proteins, indicating that TNF may activate a distinct signal transduction pathway. Examples of TNF-stimulated phosphorylation include the 27- to $28-\mathrm{kDa}$ small heat shock proteins, the $28-\mathrm{kDa}$ mRNA cap-binding protein, the epidermal growth factor (EGF) receptor, eIF-4E, 1-plastin, myosin light chain, nucleolin, stathmin, c-Abl, Rb, and p53 (11, 29-31, 55).

Several kinase activities have been reported to be increased by TNF and IL-1. These include well-defined protein kinases, such as protein kinase $A(64,79)$, protein kinase $C(14,53)$, and mitogen-activated protein (MAP) kinases (ERKs) $(28,31$, $57,74)$. As these protein kinases have been implicated in the mechanisms of signal transduction by many other extracellular stimuli, it is difficult to understand how the activation of these kinases can account for the distinctive pattern of protein phosphorylation that is induced by TNF (31). Therefore, there 
has been much interest in the role of novel protein kinases. Indeed, several protein kinase activities that are increased by treatment of cells with proinflammatory cytokines have been identified: a ceramide-activated protein kinase $(20,40,48,49)$, an hsp27 kinase (28), a $\beta$-casein kinase (28), an 85-kDa nuclear kinase (56), and tyrosine kinase activity $(37,40)$. However, these activities have not been molecularly characterized.

The purpose of this study was to investigate whether JNK protein kinases are activated in TNF-treated cells. Two JNK protein kinase isoforms ( 46 and $55 \mathrm{kDa}$ ) have been identified in HeLa cells (36). Recently, we described the molecular cloning of the $46-\mathrm{kDa}$ isoform, JNK1 (18). In this report, we describe the cloning of the $55-\mathrm{kDa}$ isoform, JNK2. In addition, we show that TNF, like UV radiation, causes JNK protein kinase activation. The activation of transcription factor AP-1 caused by UV radiation is similar to that caused by proinflammatory cytokines $(14,19,51)$. The effect on AP-1 can be accounted for by the JNK protein kinase pathway and the phosphorylation of $\mathrm{c}$-Jun within the $\mathrm{NH}_{2}$-terminal activation domain $(18,36)$. We conclude that JNK protein kinases represent an important signaling pathway that mediates actions of proinflammatory cytokines and UV radiation.

\section{MATERIALS AND METHODS}

Materials. $\left[{ }^{32} \mathrm{P}\right]$ phosphate was purchased from DupontNEN. $\left[\gamma^{-32}\right.$ P]ATP was prepared with a Gamma-Prep A kit (Promega Biotec) as described by the manufacturer. Monoclonal antibody M2, which binds the epitope Asp-Tyr-Lys-AspAsp-Asp-Asp-Lys, was purchased from IBI-Kodak. Recombinant glutathione $S$-transferase (GST) fusion proteins with c-Jun and v-Jun have been described previously (18). Recombinant human TNF- $\alpha$ was obtained from Genzyme Corp. The polyclonal rabbit JNK antibody was prepared using bacterially expressed JNK1 as an antigen.

Molecular cloning and hybridization analysis. A randomprimed probe prepared from the JNK1 CDNA (18) was used to screen a $\lambda$ ZapII HeLa cDNA library (Stratagene Inc. no. 936201). Three positive clones were obtained after screening $10^{6}$ phage. DNA sequencing of both strands of each clone was performed by using a PCR procedure employing fluorescent dideoxynucleotides and a model 373A automated sequencer (Applied Biosystems). This analysis demonstrated that these clones corresponded to overlapping cDNAs and included the complete JNK 2 coding region.

The JNK2 cDNA was cloned into the expression vector pCMV5 (6) between the XbaI and HindIII sites. A PCR-based procedure was used to insert an epitope tag (Asp-Tyr-Lys-AspAsp-Asp-Asp-Lys) between codons 1 and 2 of the JNK1 cDNA (37). The sequence of each of these constructs was confirmed by automated sequencing with a model $373 \mathrm{~A}$ DNA sequencer (Applied Biosystems).

Northern (RNA) blots were performed with $2 \mu \mathrm{g}$ of poly $(\mathrm{A})^{+}$RNA isolated from different human tissues, fractionated by denaturing agarose gel electrophoresis, and transferred onto a nylon membrane (Clontech). The blots were hybridized to probes prepared by labeling fragments of JNK1 (bp 936 to 1418) and JNK2 (bp 1270 to 1736) cDNAs with $\left[\alpha-{ }^{32} \mathrm{P}\right] \mathrm{dCTP}$ (Amersham International PLC) by random priming (Stratagene Inc.). The integrity of the mRNA samples was confirmed by hybridization to an actin probe. The blots were washed three times with $1 \times \operatorname{SSC}(0.15 \mathrm{M} \mathrm{NaCl}$ plus $0.015 \mathrm{M}$ sodium citrate) $-0.05 \%$ sodium dodecyl sulfate (SDS)-1 mM EDTA prior to autoradiography.

Tissue culture. HeLa and COS-1 cells were obtained from the American Type Culture Collection and were maintained in
Dulbecco's modified Eagle's medium supplemented with 5\% (vol/vol) fetal bovine serum (Gibco-BRL). Transient transfection of COS-1 cells was performed by using $1 \mu \mathrm{g}$ of plasmid DNA as described previously (62).

In vitro translation. Plasmids (pBluescript) containing JNK1 and JNK2 cDNAs were linearized with BamHI and transcribed with $\mathrm{T} 7$ polymerase in vitro (Promega Biotec). In vitro translation was performed by using $\left[{ }^{35}\right.$ S]methionine (Dupont-NEN) and reticulocyte lysate (Promega Biotec).

Binding assays. Binding assays were performed by incubating the JNK protein kinases with $5 \mu \mathrm{g}$ of GST-Jun in $250 \mu \mathrm{l}$ of buffer A (20 mM Tris [pH 7.4], $137 \mathrm{mM} \mathrm{NaCl,} 2$ mM EDTA, $1 \%$ Triton $\mathrm{X}-100,10 \%$ glycerol, $2 \mathrm{mM}$ pyrophosphate, $25 \mathrm{mM}$ $\beta$-glycerophosphate, $10 \mu \mathrm{g}$ of leupeptin per $\mathrm{ml}, 100 \mu \mathrm{M}$ phenylmethylsulfonyl fluoride). The complexes were collected with $10 \mu$ l of glutathione (GSH)-agarose and washed three times with $20 \mathrm{mM} N$-2-hydroxyethylpiperazine- $N^{\prime}$-2-ethanesulfonic acid (HEPES; pH 7.4)-50 mM NaCl-0.1 mM EDTA-25 $\mathrm{mM} \mathrm{MgCl} 2-0.05 \%$ Triton X-100. A fraction of the total JNK $(10 \%)$ and the bound JNK were detected after SDS-polyacrylamide gel electrophoresis (PAGE). Epitope-tagged JNK was detected by Western blot (immunoblot) analysis. In vitrotranslated JNK was detected by autoradiography (Kodak XOmat AR film) and quantitated by PhosphorImager (Molecular Dynamics Inc.) analysis. The efficiency of binding was calculated as the percentage of total JNK in the incubation that bound to GST-Jun.

Protein kinase assays. Immune-complex kinase assays using monoclonal antibody M2 or the JNK polyclonal antibody were performed by using GST-Jun as a substrate (18). Phosphorylation assays were performed in $50 \mu$ l of kinase buffer $(10 \mathrm{mM}$ $\mathrm{MgCl}_{2}-25 \mathrm{mM}$ HEPES [pH 7.4] with $50 \mu \mathrm{M}\left[\gamma^{-32} \mathrm{P}\right]$ ATP $[10$ $\mu \mathrm{Ci} / \mathrm{nmol}])$. The phosphorylation reactions were terminated after 10 min by the addition of Laemmli sample buffer. The phosphorylated proteins were resolved by SDS-PAGE, visualized by autoradiography, and quantitated by PhosphorImager (Molecular Dynamics Inc.) analysis. Control experiments demonstrated that the phosphorylation reactions were linear with time for at least $40 \mathrm{~min}$. Phosphoamino acid analysis and tryptic peptide mapping were performed as described previously (18).

Western blot analysis. Immunoblotting was performed by using Immobilon-P membranes (Millipore Corp.), probing with monoclonal antibody $\mathrm{M} 2$, and enhanced chemiluminescence detection (Amersham Inc.) as described previously (18).

Complementation assays. The HOG1 expression vector pJB17 and Saccharomyces cerevisiae JBY10 (null mutant hog1$\Delta 1$ ) were obtained from M. Gustin (15). Expression vectors for JNK1 and JNK2 were constructed by subcloning the cDNAs at the BamHI and HindIII sites of pVP16 (75). The structure of each plasmid was confirmed by automated sequencing with an Applied Biosystems model 373A machine. Strain JBY10 was transformed with the plasmids, and equal portions were spread on agar plates supplemented without and with $0.9 \mathrm{M} \mathrm{NaCl}$. Expression of JNK1 and JNK2 in the yeast cells was confirmed in control experiments by Western blot analysis.

Nucleotide sequence accession number. The sequence of the human JNK2 cDNA has been deposited in the GenBank database with accession number L31951.

\section{RESULTS}

The JNK group of protein kinases includes JNK1 and JNK2. We have identified a $46-\mathrm{kDa}$ protein kinase as a member of the JNK protein kinase group (18). To identify additional members of this group, we screened a HeLa cDNA 
(1)

(137)

(27)

(215)

(293)

(79)

(371)

(449)

(131)

(527)

(157)

(605)

(183)

(683)

(209)

(761)

(235)

(839)

(261)

(917)

(287)

(995)

(313)

(1073)

(339)

(1151)

(365)

(1229)

(391)

(1307)

(1401)

(1504)

(1607)

(1710)

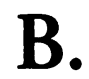

GGGCGGGCGAGGGATCTGAAACTTGCCCACCCTTCGGGATATTGCAGGACGCTGCATC ATG AGC GAC AGT AAA TGT GAC AGT CAG TTT TAT AGT GTG CAA GTG GCA GAC TCA ACC TTC ACT GTC CTA AAA CGT TAC $\begin{array}{llllllllllllllllllllllllllllll}M & S & D & S & K & C & D & S & Q & F & Y & S & V & Q & V & A & D & S & T & F & T & V & L & K & R & Y\end{array}$ CAG CAG CTG AAA CCA ATT GGC TCT GGG GCC CAA GGG ATT GTT TGT GCT GCA TTT GAT ACA GTT CTT GGG ATA AGT GTT $\begin{array}{lllllllllllllllllllllllllll}Q & Q & L & K & P & I & G & S & G & A & Q & G & I & V & C & A & A & F & D & T & V & L & G & I & S & V\end{array}$ GCA GTC AAG AAA CTA AGC CGT CCT TTT CAG AAC CAA ACT CAT GCA AAG AGA GCT TAT CGT GAA CTT GTC CTC TTA AAA $\begin{array}{lllllllllllllllllllllllllll}A & V & K & K & L & S & R & P & F & Q & N & Q & T & H & A & K & R & A & Y & R & E & L & V & L & L & K\end{array}$ TGT GTC AAT CAT AAA AAT ATA ATT AGT TTG TTA AAT GTG TTT ACA CCA CAA AAA ACT CTA GAA GAA TTT CAA GAT GTG $\begin{array}{lllllllllllllllllllllllllllllll}C & V & N & H & K & N & I & I & S & L & L & N & V & F & T & P & Q & K & T & L & E & E & F & Q & D & V\end{array}$ TAT TTG GTT ATG GAA TTA ATG GAT GCT AAC TTA TGT CAG GTT ATT CAC ATG GAG CTG GAT CAT GAA AGA ATG TCC TAC $\begin{array}{lllllllllllllllllllllllllll}Y & L & V & M & E & L & M & D & A & N & L & C & Q & V & I & H & M & E & L & D & H & E & R & M & S & Y\end{array}$ CTT CTT TAC CAG ATG CTT TGT GGT ATT AAA CAT CTG CAT TCA GCT GGT ATA ATT CAT AGA GAT TTG AAG CCT AGC AAC $\begin{array}{lllllllllllllllllllllllllll}L & L & Y & Q & M & L & C & G & I & K & H & L & H & S & A & G & I & I & H & R & D & L & K & P & S & N\end{array}$ ATT GTT GTG AAA TCA GAC TGC ACC CTG AAG ATC CTT GAC TTT GGC CTG GCC CGG ACA GCG TGC ACT AAC TTC ATG ATG $\begin{array}{llllllllllllllllllllllllll}I & V & V & K & S & D & C & T & L & K & I & L & D & F & G & L & A & R & T & A & C & T & N & F & M & M\end{array}$ ACC CCT TAC GTG GTG ACA CGG TAC TAC CGG GCG CCC GAA GTC ATC CTG GGT ATG GGC TAC AAA GAG AAC GTT GAT ATC $\begin{array}{llllllllllllllllllllllllll}T & P & Y & V & V & T & R & Y & Y & R & A & P & E & V & I & L & G & M & G & Y & K & E & N & V & D & I\end{array}$ TGG TCA GTG GGT TGC ATC ATG GGA GAG CTG GTG AAA GGT TGT GTG ATA TTC CAA GGC ACT GAC CAT ATT GAT CAG TGG $\begin{array}{llllllllllllllllllllllllllll}W & S & V & G & C & I & M & G & E & L & V & K & G & C & V & I & F & Q & G & T & D & H & I & D & Q & W\end{array}$ AAT AAA GTT ATT GAG CAG CTG GGA ACA CCA TCA GCA GAG TTC ATG AAG AAA CTT CAG CCA ACT GTG AGG AAT TAT GTC $\begin{array}{llllllllllllllllllllllllll}N & K & V & I & E & Q & L & G & T & P & S & A & E & F & M & K & K & L & Q & P & T & V & R & N & Y & V\end{array}$ GAA AAC AGA CCA AAG TAT CCT GGA ATC AAA TTT GAA GAA CTC TTT CCA GAT TGG ATA TTC CCA TCA GAA TCT GAG CGA $\begin{array}{llllllllllllllllllllllllll}E & N & R & P & K & Y & P & G & I & K & F & E & E & L & F & P & D & W & I & F & P & S & E & S & E & R\end{array}$ GAC AAA ATA AAA ACA AGT CAA GCC AGA GAT CTG TTA TCA AAA ATG TTA GTG ATT GAT CCT GAC AAG CGG ATC TCT GTA $\begin{array}{llllllllllllllllllllllllllll}D & K & I & K & T & S & Q & A & R & D & L & L & S & K & M & L & V & I & D & P & D & K & R & I & S & V\end{array}$ GAC GAA GCT CTG CGT CAC CCA TAC ATC ACT GTT TGG TAT GAC CCC GCC GAA GCA GAA GCC CCA CCA CCT CAA ATT TAT $\begin{array}{lllllllllllllllllllllllllll}D & E & A & L & R & H & P & Y & I & T & V & W & Y & D & P & A & E & A & E & A & P & P & P & Q & I & Y\end{array}$ GAT GCC CAG TTG GAA GAA AGA GAA CAT GCA ATT GAA GAA TGG AAA GAG CTA ATT TAC AAA GAA GTC ATG GAT TGG GAA $\begin{array}{llllllllllllllllllllllllll}D & A & Q & L & E & E & R & E & H & A & I & E & E & \boldsymbol{W} & K & E & L & I & Y & K & E & V & M & D & \boldsymbol{W} & E\end{array}$ GAA AGA AGC AAG AAT GGT GTT GTA AAA GAT CAG CCT TCA GAT GCA GCA GTA AGT AGC AAC GCC ACT CCT TCT CAG TCT $\begin{array}{lllllllllllllllllllllllllll}E & R & S & K & N & G & V & V & K & D & Q & P & S & D & A & A & V & S & S & N & A & T & P & S & Q & S\end{array}$ TCA TCG ATC AAT GAC ATT TCA TCC ATG TCC ACT GAG CAG ACG CTG GCC TCA GAC ACA GAC AGC AGT CTT GAT GCC TCG $\begin{array}{llllllllllllllllllllllllll}S & S & I & N & D & I & S & S & M & S & T & E & Q & T & L & A & S & D & T & D & S & S & L & D & A & S\end{array}$ ACG GGA CCC CTT GAA GGC TGT CGA TGA TAGGTTAGAAATAGCAAACCTGTCAGCATTGAAGGAACTCTCACCTCCGTGGCCTGAAATGCTTGG $\begin{array}{lllllllllllll}T & G & P & L & E & G & C & R & \ddagger\end{array}$

GAGTTGATGGAACCAAATAGAAAAACTCCATGTTCTGCATGTAAGAAACACAATGCCTTGCCCTATTCAGACCTGATAGGATTGCCTGCTTAGATGATAAAAT GAGGCAGAATATGTCTGAAGAAAAAAATTGCAAGCCACACTTCTAGAGATTTTGTTCAAGATCATTTCAGGTGAGCAGTTAGAGTAGGTGAATTTGTTPTCAAA TTGTACTAGTGACAGTTTCTCATCATCTGTAACTGTTGAGATGTATGTGCATGTGACCACAAATGCTTGCTTGGACTTGCCCATCTAGCACTTTGGAAATCAG TATTTAAATGCCAAATAATCTTCCAGGTAGTGCTGCTTCTGAAGTTATCTCTTAATCCTCTTAAGTAATTT

\begin{abstract}
JNK2 MSDSKCDSQFYSVQVADSTFTVLKRYQQLKPIGSGAQGIVCAAFDTVLGISVAVKKLSRPFQNQTHAKRAYRELVLLKCVNHKNI ISLLNVFTPQKTLEEFQD

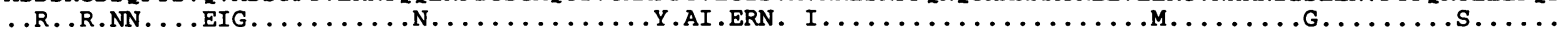
$\mathbf{v}$ VIA VIB vrI

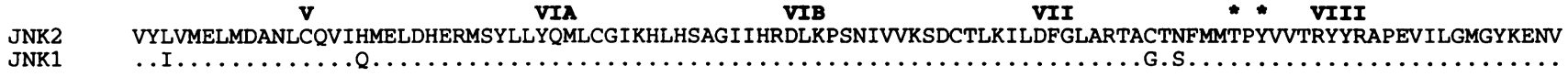
IX
DIWSVGCIMGELVKGCVIFOGTDHIDQWNKVIEQLGTPSAEFMKKLQPTVRNYVENRPKYPGIKFEELFPDWIFPSESERDKIKTSOARDLLSKMLVIDPDKR

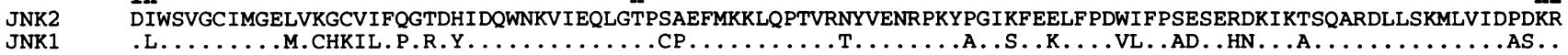

JNK2 ISVDEALRHPY ITVWYDPAEAEAPPPQIYDAQLEEREHAIEEWKELIYKEVMDWEERSKNGVVKDQPSDAAVSSNATPSQSSSINDISSMSTEQTLASDTDSS JNK1

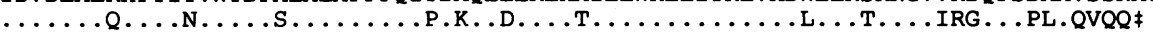

FIG. 1. Identification of JNK2 as a member of the JNK protein kinase group. (A) Nucleotide and deduced protein sequences of the JNK2 cDNA. In-frame stop codons in the 5' and 3' untranslated regions are underlined. (B) Deduced sequence of JNK2 aligned with the JNK1 sequence, using the PILEUP program (Wisconsin Genetics Computer Group). Residues that are identical are indicated with periods. The carboxyl termini encoded by stop codons in the cDNA sequence are indicated ( $\ddagger)$. The protein kinase subdomains located within the deduced protein sequence are illustrated, and the conserved tyrosine and threonine phosphorylation sites are indicated with asterisks (18).
\end{abstract}




\section{A. Western Blot Analysis}

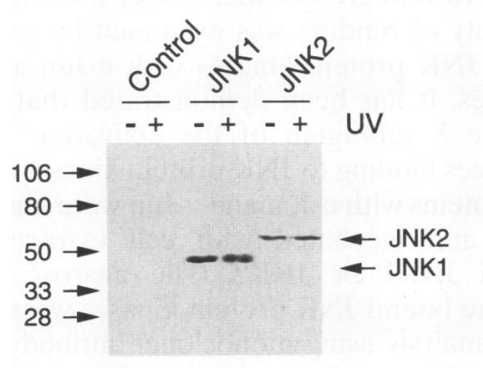

B. Protein Kinase Assay

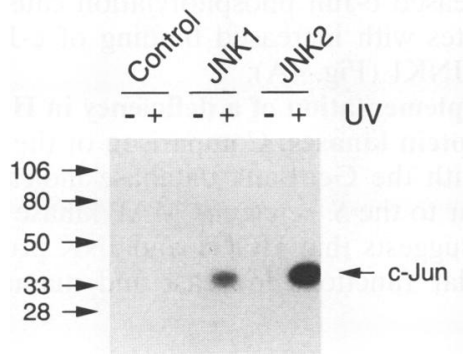

FIG. 2. UV radiation activates JNK protein kinases. Epitopetagged JNK1 and JNK2 proteins were expressed in COS cells. Mocktransfected cells were used in control experiments. The cells were either exposed or not exposed to $80 \mathrm{~J}$ of UV-C per $\mathrm{m}^{2}$ and incubated for $1 \mathrm{~h}$ at $37^{\circ} \mathrm{C}$. The JNK protein kinases were isolated by immunoprecipitation with monoclonal antibody M2 and SDS-PAGE. The level of expression of JNK protein kinases was examined by Western blot analysis using monoclonal antibody $\mathrm{M} 2$ and enhanced chemiluminescence detection (A). JNK protein kinase activity was measured with an immune-complex kinase assay and GST-Jun (residues 1 to 79) as the substrate (B). Locations of molecular mass standards are shown at the left in kilodaltons.

library cloned in the vector $\lambda$ ZapII $\left(10^{6}\right.$ plaques). Three positive clones were identified. DNA sequence analysis revealed that these clones corresponded to overlapping cDNAs. The sequence of the largest clone $(1,782 \mathrm{bp})$ contained the complete open reading frame of a protein kinase (JNK2) that is similar to JNK1 (Fig. 1). Comparison of the nucleotide sequences of JNK1 and JNK2 indicates that these protein kinases are the products of distinct genes. However, comparison of the deduced protein sequence of JNK1 and JNK2 indicates a high level of sequence identity within the protein kinase domain (Fig. 1B). Significantly, these JNK isoforms share the Thr-183-Pro-Tyr-185 motif that corresponds to the activating Thr and Tyr phosphorylation sites of JNK1 (18). Several amino acid differences between JNK1 and JNK2 are located within the kinase domain. However, the most obvious difference between these protein kinases is that JNK2 has a larger COOH-terminal extension than JNK1 (Fig. 1B).

To examine the expression of the JNK isoforms, we performed Northern blot analysis of mRNA isolated from different human tissues. Isoform-specific probes were prepared from nonhomologous regions of the JNK1 and JNK2 cDNAs (3' untranslated region). A low level of expression of JNK1 and JNK2 was observed in human brain, heart, kidney, lung, pancreas, and skeletal muscle (data not shown). Together, these data indicate that the JNK1 and JNK2 protein kinases are widely expressed in human tissues.
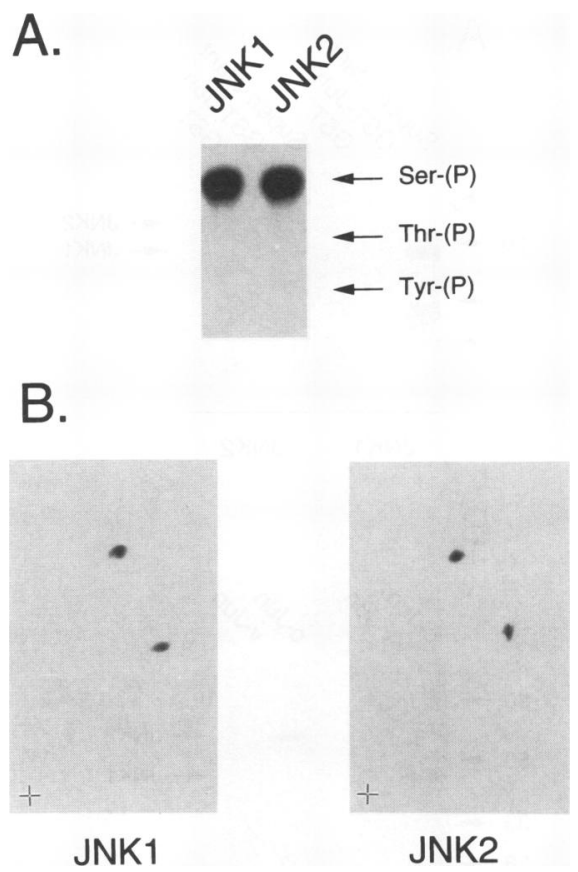

FIG. 3. Phosphorylation of c-Jun on Ser-63 and Ser-73 by JNK protein kinases. Epitope-tagged JNK1 and JNK2 proteins were expressed in COS cells. The cells were exposed to $80 \mathrm{~J}$ of UV-C per $\mathrm{m}^{2}$ and incubated for $1 \mathrm{~h}$ at $37^{\circ} \mathrm{C}$. The JNK protein kinases were isolated by immunoprecipitation with monoclonal antibody M2. An immunecomplex kinase assay was performed with recombinant c-Jun as a substrate. The phosphorylated c-Jun was analyzed by phosphoamino acid analysis (A) and tryptic phosphopeptide mapping (B). The origin of each peptide maps is illustrated with a cross at the lower left corner of each map. The horizontal dimension was electrophoresis, and the vertical dimension was chromatography.

Activation of JNK protein kinases by $\mathrm{UV}$ radiation. We expressed epitope-tagged JNK1 and JNK2 protein kinases in COS cells. Western blot analysis demonstrated the presence of the 46-kDa JNK1 and the 55-kDa JNK2 isoforms (Fig. 2A). A higher level of expression of JNK1 than of JNK2 was observed in the transient transfection assays. This difference in the level of expression was confirmed in control experiments by immunoprecipitation of the JNK isoforms from cells metabolically labeled with $\left[{ }^{35} \mathrm{~S}\right]$ methionine (data not shown).

JNK protein kinase activity was measured by immunoprecipitation of the recombinant JNK proteins with monoclonal antibody M2. It was found that both JNK isoforms phosphorylated the $\mathrm{NH}_{2}$-terminal activation domain of c-Jun (Fig. 2B). Exposure of the cells to UV radiation caused a marked increase in JNK protein kinase activity. Interestingly, the phosphorylation of c-Jun caused by JNK2 was more efficient than that caused by JNK1. Quantitation of these data by PhosphorImager analysis demonstrated that the specific activity of JNK 2 was approximately 10 -fold greater than that of JNK1.

JNK1 and JNK2 protein kinases phosphorylate c-Jun at Ser-63 and Ser-73. The increased phosphorylation of c-Jun observed in experiments using JNK2 compared with JNK1 may result from the phosphorylation of different sites by these protein kinases. We therefore examined the sites of c-Jun phosphorylation by JNK1 and JNK2 by phosphoamino acid analysis and tryptic phosphopeptide mapping. Both protein kinases were found to phosphorylate c-Jun exclusively on Ser 


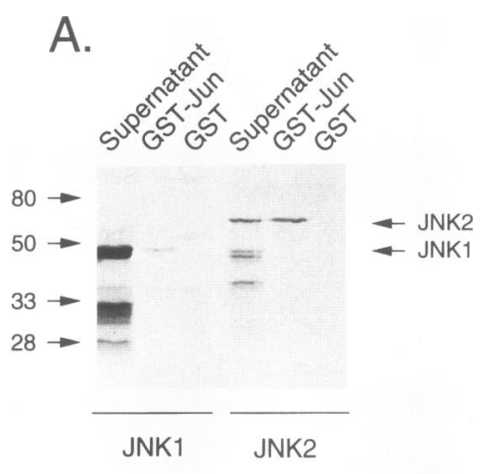

B.

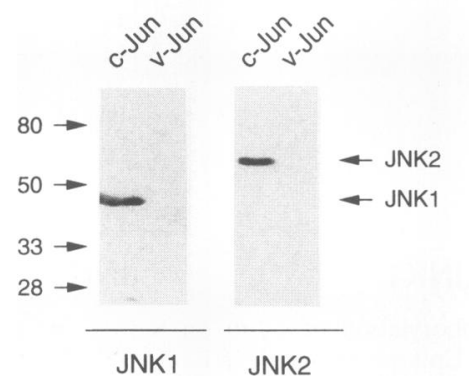

FIG. 4. JNK protein kinases bind to the c-Jun $\mathrm{NH}_{2}$-terminal activation domain. (A) Labeled JNK1 and JNK2 were prepared by in vitro translation in the presence of ${ }^{35}$ S $]$ methionine. The binding of the JNK proteins to the activation domain of c-Jun was measured by incubation with GST-c-Jun immobilized on GSH-agarose. Control experiments to investigate nonspecific interactions were performed with immobilized GST. JNK present in the supernatant fraction and JNK bound to GST-Jun or GST were analyzed by PAGE. An autoradiograph of the dried gel is shown. Locations of molecular mass standards are shown at the left in kilodaltons. (B) A soluble extract was prepared from cells expressing epitope-tagged JNK1 or JNK2. The binding of the JNK proteins was measured by incubation of the cell extracts with GST-cJun or GST-v-Jun immobilized on GSH-agarose. JNK bound to c-Jun or v-Jun was analyzed by Western blotting with monoclonal antibody M2. Locations of molecular mass standards are shown at the left in kilodaltons.

(Fig. 3A). The tryptic phosphopeptide maps of c-Jun phosphorylated by JNK1 and JNK2 were similar. The two phosphopeptides observed have previously been demonstrated to correspond to the phosphorylation of c-Jun at Ser-63 and Ser-73 $(7,18,54,65,66)$. Together, these data demonstrate that JNK1 and JNK2 phosphorylate the same sites within the $\mathrm{NH}_{2}$-terminal activation domain of c-Jun.

JNK protein kinases bind to the $\mathbf{N H}_{\mathbf{2}}$-terminal activation domain of c-Jun. We have previously demonstrated that JNK1 binds to the activation domain of c-Jun (18). The higher protein kinase activity of JNK2 (Fig. 2) may therefore reflect the increased binding of this isoform to c-Jun compared with JNK1. We therefore examined the association of both JNK isoforms with c-Jun. Labeled JNK1 and JNK2 prepared by in vitro translation were incubated with GST or GST-Jun immobilized on GSH-agarose. The bound JNK proteins were detected after extensive washing by SDS-PAGE and autoradiography. Figure 4A shows that both JNK isoforms bound to GST-Jun but failed to bind to GST. Interestingly, only the full-length JNK protein kinases obtained from the in vitro translation were found to bind to GST-Jun. Quantitation by
PhosphorImager analysis demonstrated that JNK2 binding was approximately 10 -fold greater than JNK1 binding.

The specificity of binding was examined by comparing the interaction of JNK protein kinases with c-Jun and v-Jun. In previous studies, it has been demonstrated that v-Jun has a deletion in the $\delta$ subregion of the activation domain that markedly reduces binding to JNK protein kinases $(2-4,18,36)$. GST fusion proteins with c-Jun and v-Jun were immobilized on GSH-agarose and incubated with cell extracts containing epitope-tagged JNK1 or JNK2. The agarose beads were washed, and the bound JNK protein kinases were detected by Western blot analysis using monoclonal antibody M2. Figure 4B shows that $\mathrm{v}$-Jun is defective in binding both JNK isoforms.

Together, these data demonstrate that JNK1 and JNK2 bind to the $\mathrm{NH}_{2}$-terminal activation domain of c-Jun but not to v-Jun. The increased c-Jun phosphorylation caused by JNK2 (Fig. 2) correlates with increased binding of c-Jun to JNK2 compared with JNK1 (Fig. 4A).

Selective complementation of a deficiency in HOG1 expression by JNK protein kinases. Comparison of the sequence of human JNK1 with the GenBank database indicates that this enzyme is similar to the $S$. cerevisiae MAP kinase HOG1 (18). This similarity suggests that HOG1 and JNK protein kinases may serve similar functions in yeast and mammalian cells,

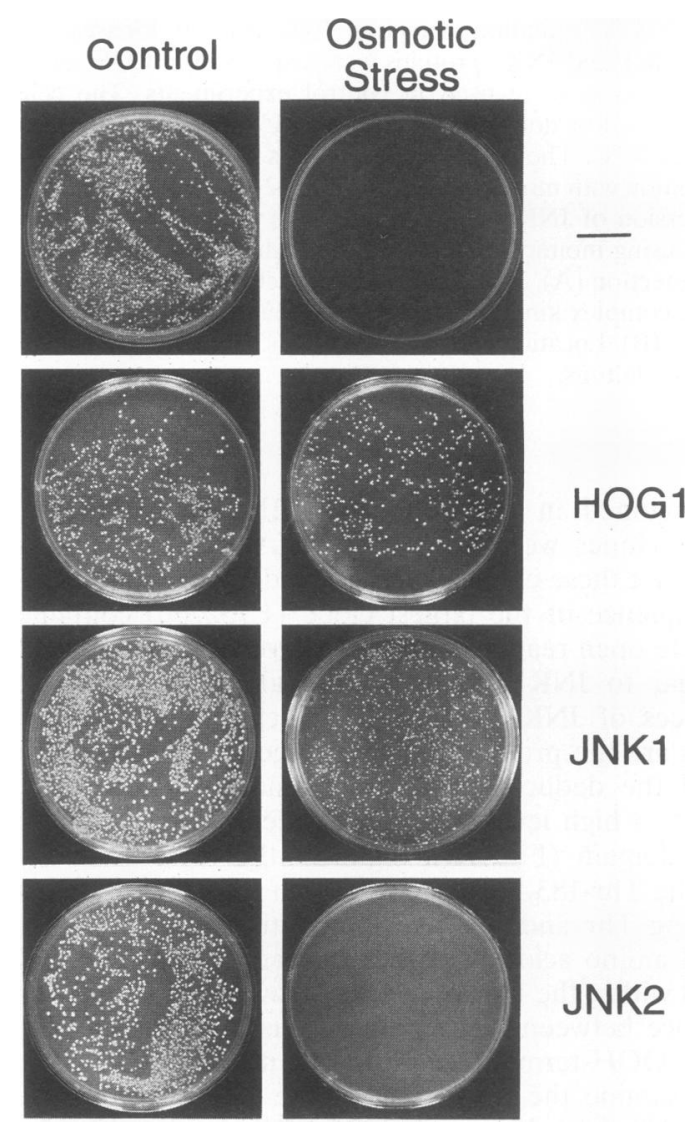

FIG. 5. A deficiency in the expression of the MAP kinase HOG1 in $S$. cerevisiae is complemented by human JNK1. Yeast cells lacking the protein kinase HOG1 were transformed with an empty expression vector (-) and spread on agar plates supplemented without (control) or with $0.9 \mathrm{M} \mathrm{NaCl}$ (osmotic stress). Other cultures of yeast cells were transformed with plasmid vectors encoding HOG1, JNK1, and JNK2. Photographs of representative plates showing the growth of yeast colonies are presented. 


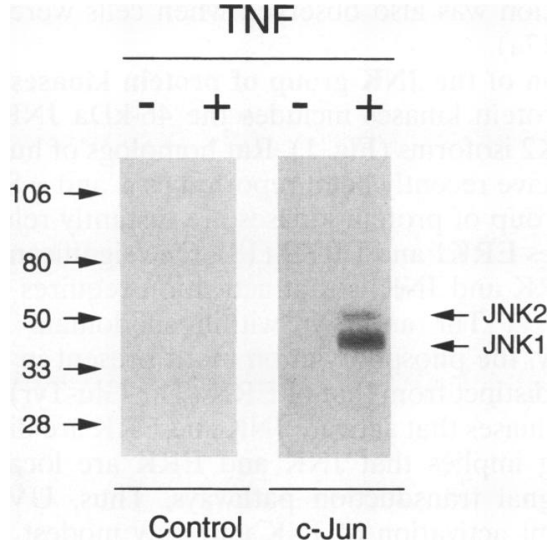

FIG. 6. TNF activates JNK1 and JNK2. HeLa cells were incubated with $10 \mathrm{ng}$ of TNF- $\alpha$ per $\mathrm{ml}$ for $15 \mathrm{~min}$ at $37^{\circ} \mathrm{C}$. JNK protein kinases were isolated by immunoprecipitation with a polyclonal JNK antibody. The protein kinase activity in the immune complexes was detected by using an in-gel assay in the absence (control) and presence of the substrate c-Jun. Locations of molecular mass standards are shown at the left in kilodaltons.

respectively. To test this hypothesis, we examined whether human JNK1 or JNK2 is able to complement a deficiency in HOG1 expression. Yeast cells lacking HOG1 (null mutant hog $1-\Delta 1$ ) are sensitive to osmotic stress and do not grow on high-osmolarity media (15). Transfection of the hogl- $\Delta 1 \mathrm{mu}-$ tant with an expression vector encoding HOG1 rescues this growth defect (Fig. 5). The hog1- $\Delta 1$ mutant was not rescued by transfection with an expression vector encoding the human MAP kinase ERK2 (25). However, the hog1- 11 mutant was rescued when the cells were transfected with a JNK1 expression vector (Fig. 5). The specificity of the complementation by JNK1 was confirmed by the demonstration that catalytically inactive JNK1 (Thr-183-Pro-Tyr-185) substituted with Ala183-Pro-Phe-185 [18]) did not complement the hogl- $\Delta 1 \mathrm{mu}-$ tant (25). The complementation by wild-type JNK1 indicates that this kinase can functionally substitute for HOG1 in yeast cells (25). In contrast, it was found that JNK2 did not complement the hog1- $\Delta 1$ mutant (Fig. 5). Control experiments using Western blot analysis demonstrated that both JNK isoforms were expressed in yeast cells. The lack of complementation by JNK 2 therefore reflects a difference in the properties of JNK1 and JNK2.

Together, these data demonstrate that human JNK1 (but not JNK2) is able to substitute for the HOG1 protein kinase in yeast cells. This difference in complementation provides evidence that the in vivo functions of JNK1 and JNK2 are distinct. This conclusion is consistent with the observation that these JNK isoforms do not have identical biochemical properties (Fig. 2 and 4).

TNF activates the JNK protein kinase signal transduction pathway. UV radiation causes potent activation of JNK protein kinases (Fig. 2). In contrast, the JNK signal transduction pathway is only modestly activated by growth factors (e.g., EGF), activated Ha-Ras, and phorbol ester (18). A significant question therefore concerns the identity of physiological inducers of the JNK protein kinase pathway. As JNK activates c-Jun, candidate inducers of the JNK pathway include agents that cause sustained induction of c-Jun, such as the proinflammatory cytokine TNF- $\alpha$ (14). We therefore tested the hypothesis that TNF- $\alpha$ causes JNK activation.

We examined JNK activation in HeLa cells treated with

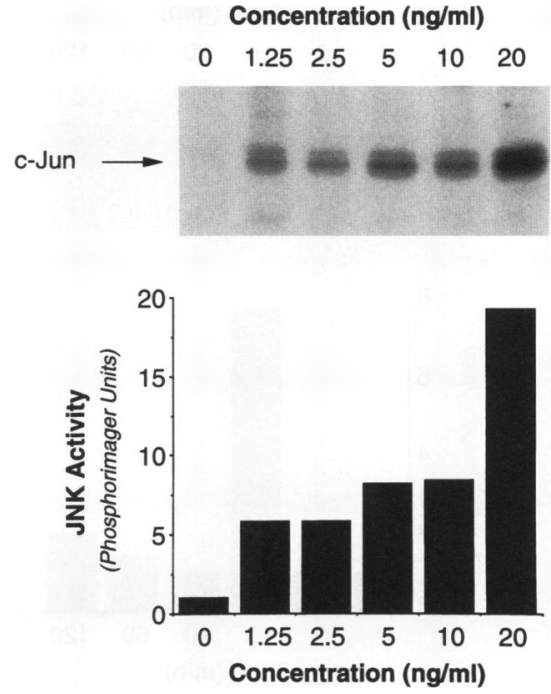

FIG. 7. Dose response of TNF-activated JNK protein kinase activity. HeLa cells were incubated for $15 \mathrm{~min}$ with different concentrations of TNF- $\alpha$ at $37^{\circ} \mathrm{C}$. JNK protein kinases were isolated by immunoprecipitation with a polyclonal JNK antibody. The protein kinase activity in the immune complexes was measured by using recombinant c-Jun as a substrate. The c-Jun was isolated by SDS-PAGE and visualized by autoradiography. The extent of phosphorylation was measured with a PhosphorImager and is presented in arbitrary (PhosphorImager) units.

TNF- $\alpha$. The JNK protein kinases were isolated by immunoprecipitation with a polyclonal JNK antibody, and protein kinase activity in the immunoprecipitates was examined after SDS-PAGE using an in-gel protein kinase assay with c-Jun as a substrate. It was found that TNF- $\alpha$ activated both the $46-\mathrm{kDa}$ JNK1 and 55-kDa JNK2 protein kinases (Fig. 6).

The effect of TNF- $\alpha$ concentration on JNK activation was examined in an immune-complex protein kinase assay with the substrates c-Jun and $\left[\gamma-{ }^{32} \mathrm{P}\right]$ ATP. JNK activation was observed when the HeLa cells were incubated with $1.25 \mathrm{ng}$ of TNF- $\alpha$ per $\mathrm{ml}$ (Fig. 7). A further increase in JNK activation was found when the cells were incubated with higher concentrations of TNF- $\alpha$. The time course of JNK activation was investigated in experiments using HeLa cells incubated with $10 \mathrm{ng}$ of TNF- $\alpha$ per ml. A rapid and marked increase in JNK activity within 15 min of treatment with TNF- $\alpha$ was observed (Fig. 8). JNK activity then declined to control levels $30 \mathrm{~min}$ after TNF- $\alpha$ treatment. A lower but sustained increase in JNK activity was observed at later times of TNF- $\alpha$ treatment. Together, these data establish that the JNK protein kinase pathway is activated by the proinflammatory cytokine TNF- $\alpha$.

\section{DISCUSSION}

Signal transduction by proinflammatory cytokines. One important action of proinflammatory cytokines is the regulation of gene expression. TNF (and IL-1) induce the expression of multiple cytokines, such as colony-stimulating factors, IL-2, IL-6, IL-8, hepatocyte growth factor, TGF- $\alpha$, nerve growth factor, $\beta$-endorphin, and Gro-related factors $(23,32,33,41,52$, $58,67,78)$. TNF has also been shown to induce IL-1 expression (27). Increased expression of proteins encoded by immediateearly genes (e.g., c-Jun), cytokine receptors (e.g., IL-2 receptor), growth factor receptors (e.g., the EGF receptor), major histocompatibility complex (classes I and II), and collagenase have been reported $(14,42,58,61)$. These changes in gene 

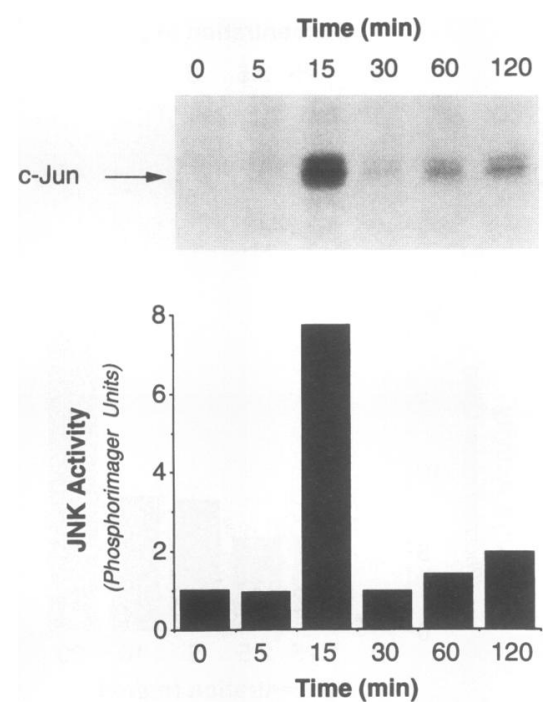

FIG. 8. Time course of JNK protein kinase activation by TNF. HeLa cells were incubated with $10 \mathrm{ng}$ of TNF- $\alpha$ per ml for different times at $37^{\circ} \mathrm{C}$. JNK protein kinases were isolated by immunoprecipitation with a polyclonal JNK antibody. The protein kinase activity in the immune complexes was measured by using recombinant c-Jun as a substrate. The c-Jun was isolated by SDS-PAGE and visualized by autoradiography. The extent of phosphorylation was measured with a PhosphorImager and is presented in arbitrary (PhosphorImager) units.

expression are mediated by the regulation of several transcription factors. Indeed, effects of TNF and IL-1 on AP-1 (14, 50, 51), NF-кB $(12,39,63)$, and C/EBP (5) have been described. Recent studies have established a primary role for increased AP-1 activity. Examples include the increased expression of IL-2 (51), $\beta$-endorphin (23), c-Jun (50), the monocyte chemoattractant JE (32), and the hyaluronan-binding protein TSG6 (45). Together, these data demonstrate that AP-1 is a physiologically significant target of the signal transduction pathway activated by proinflammatory cytokines.

Homodimers of c-Jun or heterodimers of c-Jun with partner proteins (e.g., c-Fos) bind to AP-1 sites $(1,43)$. Significantly, the proinflammatory cytokines TNF and IL-1 cause a marked increase in c-Jun expression $(14,51)$. The increased expression of c-Jun is mediated by two cis-acting elements (AP-1 sites) in the c-Jun promoter $(50)$. This observation indicates that the induction of c-Jun expression is dependent on the activation of preexisting complexes of the AP-1 transcription factor (38). One mechanism of activation is mediated by the phosphorylation of the $\mathrm{NH}_{2}$-terminal activation domain of c-Jun (10). Indeed, detailed studies have demonstrated that the phosphorylation of c-Jun within the $\mathrm{NH}_{2}$-terminal domain at Ser-63 and Ser-73 causes increased transcriptional activity $(54,65,66)$. These regulatory sites of phosphorylation are substrates for JNK protein kinases (36). Two JNK protein kinase isoforms (46 and $55 \mathrm{kDa}$ ) have been identified in HeLa cells (36). Recently, we molecularly cloned the $46-\mathrm{kDa}$ isoform, JNK1 (18). Here, we describe the cloning of the $55-\mathrm{kDa}$ isoform, JNK2.

As JNK protein kinases phosphorylate sites on c-Jun that increase transcriptional activity, JNK activation provides a signaling mechanism that regulates AP-1. Thus, the increased AP-1 activity observed in TNF-treated cells may be mediated by the JNK signal transduction pathway. Consistent with this hypothesis, incubation of cells with TNF caused a marked increase in JNK protein kinase activity (Fig. 6). Interestingly,
JNK activation was also observed when cells were incubated with IL-1 (17a).

Regulation of the JNK group of protein kinases. The JNK group of protein kinases includes the $46-\mathrm{kDa}$ JNK1 and the $55-\mathrm{kDa}$ JNK2 isoforms (Fig. 1). Rat homologs of human JNK1 and JNK2 have recently been reported as $\alpha$ and $\gamma$ SAPK (44). The JNK group of protein kinases are distantly related to the MAP kinases ERK1 and ERK2 (18). One significant similarity between ERK and JNK is that activation requires dual phosphorylation at Thr and Tyr within subdomain VIII (18). Interestingly, the phosphorylation motif present in JNK (ThrPro-Tyr) is distinct from that of ERK (Thr-Glu-Tyr). Similarly, the kinase kinases that activate JNK and ERK are distinct (18). This finding implies that JNK and ERK are located within separate signal transduction pathways. Thus, UV radiation causes potent activation of JNK and only modest changes in ERK activity (18). In contrast, EGF, activated Ha-Ras, and phorbol ester cause marked ERK activation but only a small increase in JNK activity (18). Here we demonstrate that the JNK group of protein kinases are activated by the proinflammatory cytokine TNF. A similar conclusion has recently been reported by Kyriakis et al. (44).

It is possible that $\mathrm{JNK} 1$ and $\mathrm{JNK} 2$ have redundant functions in the cell. However, the observation that JNK1, but not JNK2, complements a defect in the expression of the HOG1 MAP kinase in $S$. cerevisiae demonstrates that these JNK isoforms have distinct properties in vivo. Evidence for distinct functions of JNK1 and JNK2 was also obtained by comparison of the in vitro biochemical properties of these JNK isoforms. Thus, the binding of c-Jun to JNK2 was significantly greater than the binding to JNK1 (Fig. 4). Similarly, JNK2 caused greater phosphorylation of c-Jun than did JNK1 (Fig. 2). The structural differences between JNK1 and JNK2 that may account for these properties include (i) changes in the protein kinase domain and (ii) the divergent $\mathrm{COOH}$-terminal sequences (Fig. 1B).

Together, these data suggest that the catalytic activity of JNK2 is greater than that of JNK1. However, it is also possible that these data reflect a difference in the substrate specificity of these JNK isoforms. Thus, c-Jun may be a preferential physiological substrate for JNK2, while JNK1 targets a different substrate. The identification of additional JNK substrates will be required to test this hypothesis. Although it is likely that several substrates for JNK protein kinases exist, at present c-Jun is the only substrate that has been identified $(18,44)$. An important goal for future studies will be to identify additional JNK substrates. A comparison of the phosphorylation of these substrates by JNK1 and JNK2 will be necessary to resolve whether the difference in c-Jun phosphorylation by these isoforms is the result of a difference in catalytic activity or substrate specificity.

Conclusions. The JNK protein kinase pathway is activated by exposure of cells to several forms of environmental stress, including UV radiation and proinflammatory cytokines. TNF and UV radiation have been demonstrated to cause cell cycle growth arrest and apoptosis. The role of JNK activation in these processes has not been established. However, JNK may be a component of a signal transduction pathway that leads to altered expression of stress-related genes. Thus, JNK activation may occur in response to exposure to several forms of environmental stress.

\section{ACKNOWLEDGMENTS}

M. Gustin is thanked for providing plasmids and yeast strains. M. Dickens is thanked for preparing the JNK antisera. M. Wysk and $Z$. Galcheva-Gargova provided advice about screening cDNA libraries 
and complementation assays, respectively. The technical assistance of I.-H. Wu is greatly appreciated. The excellent secretarial assistance of M. Shepard is acknowledged.

This study was supported by a grant from the National Cancer Institute. R.J.D. is an Investigator of the Howard Hughes Medical Institute.

\section{REFERENCES}

1. Abate, C., and T. Curran. 1990. Encounters with Fos and Jun on the road to AP-1. Semin. Cancer Biol. 1:19-26.

2. Adler, V., C. C. Franklin, and A. S. Kraft. 1992. Phorbol esters stimulate the phosphorylation of c-Jun but not v-Jun: regulation by the N-terminal delta domain. Proc. Natl. Acad. Sci. USA 89:53415345.

3. Adler, V., A. Polotskaya, F. Wagner, and A. S. Kraft. 1992. Affinity-purified c-Jun amino-terminal protein kinase requires serine/threonine phosphorylation for activity. J. Biol. Chem. 267: 17001-17005.

4. Adler, V., T. Unlap, and A. S. Kraft. 1994. A peptide encoding the c-Jun $\delta$ domain inhibits the activity of a c-jun amino terminal protein kinase. J. Biol. Chem. 269:11186-11191.

5. Akira, S., J. Isshiki, T. Sugita, O. Tanabe, S. Kinoshita, Y. Nishio, T. Nakajima, T. Hirano, and T. Kishimoto. 1990. A nuclear factor for IL-6 expression (NF-IL-6) is a member of the C/EBP family. EMBO J. 9:1897-1906.

6. Andersson, S., D. L. Davis, H. Dahlbäck, H. Jörnvall, and D. W. Russell. 1989. Cloning, structure, and expression of the mitochondrial cytochrome P-450 sterol 26-hydroxylase, a bile acid biosynthetic enzyme. J. Biol. Chem. 264:8222-8229.

7. Baker, S. J., T. K. Kerppola, D. Luk, M. T. Vandenberg, D. R. Marshak, T. Curran, and C. Abate. 1992. Jun is phosphorylated by several protein kinases at the same sites that are modified in serum-stimulated fibroblasts. Mol. Cell. Biol. 12:4694-4705.

8. Banner, D. W., A. D'Arcy, W. Janes, R. Gentz, H.-J. Schoenfeld, C. Broger, H. Loetscher, and W. Lesslauer. 1993. Crystal structure of the soluble human $55 \mathrm{kDa}$ TNF receptor-human TNF- $\beta$ complex: implications for TNF receptor activation. Cell 73:431-445.

9. Beutler, B., and A. Cerami. 1988. Tumor necrosis, cachexia, shock and inflammation: a common mediator. Annu. Rev. Biochem. 57:505-518.

10. Binetruy, B., T. Smeal, and M. Karin. 1991. Ha-Ras augments c-Jun activity and stimulates phosphorylation of its activation domain. Nature (London) 351:122-127.

11. Bird, T. A., and J. Saklatvala. 1989. IL-1 and TNF transmodulate epidermal growth factor receptors by a protein kinase C-independent mechanism. J. Immunol. 142:126-133.

12. Bomsztyk, K., B. Toivola, D. W. Emery, J. W. Rooney, S. K. Dower, N. A. Rachie, and C. H. Sibley. 1990. Role of cAMP in interleukin1 -induced kappa light chain gene expression in murine B cell line. J. Biol. Chem. 265:9413-9417.

13. Brakebusch, C., Y. Nophar, O. Kemper, H. Engelmann, and D. Wallach. 1992. Cytoplasmic truncation of the p55 tumor necrosis factor (TNF) receptor abolishes signaling, but not the induced shedding of the receptor. EMBO J. 11:943-950.

14. Brenner, D. A., M. O'Hara, P. Angel, M. Chojkier, and M. Karin. 1989. Prolonged activation of jun and collagenase genes by tumour necrosis factor- $\alpha$. Nature (London) 337:661-663.

15. Brewster, J. L., T. de Valoir, N. D. Dwyer, E. Winter, and M. C. Gustin. 1993. An osmosensing signal transduction pathway in yeast. Science 259:1760-1763.

16. Carswell, E. A., L. J. Old, R. L. Kassel, S. Green, N. Fiore, and B. Williamson. 1975. An endotoxin-induced serum factor that causes necrosis of tumors. Proc. Natl. Acad. Sci. USA 72:3666-3670.

17. Davis, R. J. 1993. The mitogen-activated protein kinase signal transduction pathway. J. Biol. Chem. 268:14553-14556.

17a.Dérijard, B., and R. Davis. Unpublished data.

18. Dérijard, B., M. Hibi, I.-H. Wu, T. Barrett, B. Su, T. Deng, M. Karin, and R. J. Davis. 1994. JNK1: a protein kinase stimulated by UV light and Ha-Ras that binds and phosphorylates the c-Jun activation domain. Cell 76:1025-1037.

19. Devary, Y., R. A. Gottlieb, L. F. Lau, and M. Karin. 1991. Rapid and preferential activation of the c-jun gene during the mammalian UV response. Mol. Cell. Biol. 11:2804-2811.
20. Dressler, K. A., S. Mathias, and R. N. Kolesnick. 1992. Tumor necrosis factor-alpha activates the sphingomyelin signal transduction pathway in a cell-free system. Science 255:1715-1718.

21. Engelmann, H., H. Holtmann, C. Brakebusch, Y. S. Avni, I. Sarov, Y. Nophar, E. Hadas, O. Leitner, and D. Wallach. 1990. Antibodies to a soluble form of a tumor necrosis factor (TNF) receptor have TNF-like activity. J. Biol. Chem. 265:14497-14504.

22. Espevik, T., M. Brockhaus, H. Loetscher, U. Nonstad, and R. Shalaby. 1990. Characterization of binding and biological effects of monoclonal antibodies against a human tumor necrosis factor receptor. J. Exp. Med. 171:415-426.

23. Fagarasan, M., F. Aiello, K. Muegge, S. K. Durum, and J. Axelrod. 1990. Interleukin 1 induces $\beta$-endorphin secretion via Fos and Jun in At-20 pituitary cells. Proc. Natl. Acad. Sci. USA 87:7871-7874.

24. Fiers, W. 1991. Tumor necrosis factor: characterization at the molecular, cellular and in vivo level. FEBS Lett. 285:199-215.

25. Galcheva-Gargova, Z., B. Dérijard, I.-H. Wu, and R. J. Davis. 1994. An osmosensing signal transduction pathway in mammalian cells. Science 265:806-808.

26. Goeddel, D. V., B. B. Aggarwal, P. W. Gray, D. W. Leung, G. E. Nedwin, M. A. Palladino, J. S. Patton, D. Pennica, H. M. Shepard, B. J. Sugarman, and G. H. W. Wong. 1986. Tumor necrosis factors: gene structure and biological activities. Cold Spring Harbor Symp. Quant. Biol. 51:597-609.

27. Gorospe, M., S. Kumar, and C. Baglioni. 1993. Tumor necrosis factor increases stability of interleukin-1 mRNA by activating protein kinase C. J. Biol. Chem. 268:6214-6220.

28. Guesdon, F., N. Freshney, R. J. Waller, L. Rawlinson, and J. Saklatvala. 1993. Interleukin 1 and tumor necrosis factor stimulate two novel protein kinases that phosphorylate the heat shock protein hsp27 and beta-casein. J. Biol. Chem. 268:4236-4243.

29. Guy, G. R., J. Cairns, S. B. Ng, and Y. H. Tan. 1993. Inactivation of a redox-sensitive protein phosphatase during the early events of tumor necrosis factor/interleukin 1 signal transduction. J. Biol. Chem. 268:2141-2148.

30. Guy, G. R., X. Cao, S. P. Chua, and Y. H. Tan. 1992. Okadaic acid mimics multiple changes in early protein phosphorylation and gene expression induced by tumor necrosis factor or interleukin-1. J. Biol. Chem. 267:1846-1852.

31. Guy, G. R., S. P. Chua, N. S. Wong, S. B. Ng, and Y. H. Tan. 1991. Interleukin 1 and tumor necrosis factor activate common multiple protein kinases in human fibroblasts. J. Biol. Chem. 266:1434314352.

32. Hanazawa, S., A. Takeshita, S. Amano, T. Semba, T. Nirazuka, H. Katoh, and S. Kitano. 1993. Tumor necrosis factor- $\alpha$ induces expression of monocyte chemoattractant JE via fos and jun genes in clonal osteoblastic MC3T3-E1 cells. J. Biol. Chem. 268:95269532.

33. Hattori, A., E. Tanaka, K. Murase, N. Ishida, Y. Chatani, M. Tsujimoto, K. Hayashi, and M. Kohno. 1993. Tumor necrosis factor stimulates the synthesis and secretion of biologically active nerve growth factor in non-neuronal cells. J. Biol. Chem. 268: 2577-2582.

34. Heller, R. A., K. Song, and N. Fan. 1993. Cytotoxicity by tumor necrosis factor is mediated by both p55 and p70 receptors. Cell 73:216.

35. Heller, R. A., K. Song, N. Fan, and D. J. Chang. 1992. The p70 tumor necrosis factor receptor mediates cytotoxicity. Cell 70:4756.

36. Hibi, M., A. Lin, T. Smeal, A. Minden, and M. Karin. 1993. Identification of an oncoprotein- and UV-responsive protein kinase that bind and potentiate the c-Jun activation domain. Genes Dev. 7:2135-2148.

37. Ho, S. N., H. D. Hunt, R. M. Horton, J. K. Pullen, and L. R. Pease. 1989. Site-directed mutagenesis by overlap extension using the polymerase chain reaction. Gene 77:51-59.

38. Hunter, T., and M. Karin. 1992. The regulation of transcription by phosphorylation. Cell 70:375-387.

39. Iwasaki, T., Y. Uehara, L. Graves, N. Rachie, and K. Bromsztyk. 1992. Herbimycin A blocks IL-1-induced NF- $\mathrm{B}$ B DNA binding activity in lymphoid cell lines. FEBS Lett. 298:240-244.

40. Joseph, C. K., H.-S. Byun, R. Bittman, and R. N. Kolesnick. 1993. Substrate recognition by ceramide-activated protein kinase. $\mathrm{J}$. 
Biol. Chem. 268:20002-20006.

41. Joshi-Barve, S. S., V. V. Rangnekar, S. F. Sells, and V. M. Rangnekar. 1993. Interleukin-1 inducible expression of gro- $\beta$ via NF-kB activation is dependent upon tyrosine kinase signaling. J. Biol. Chem. 268:18018-18029.

42. Kalthoff, H., C. Roeder, M. Brockhaus, H.-G. Thiele, and W. Schmiegel. 1993. Tumor necrosis factor (TNF) up-regulates the expression of $\mathrm{p} 75$ but not $\mathrm{p} 55$ TNF receptors, and both receptors mediate, independently of each other, up-regulation of transforming growth factor- $\alpha$ and epidermal growth factor receptor mRNA. J. Biol. Chem. 268:2762-2766.

43. Karin, M. 1992. Signal transduction from cell surface to nucleus in development and disease. FASEB J. 6:2581-2590.

44. Kyriakis, J. M., P. Banerjee, E. Nikolakaki, T. Dai, E. A. Rubie, M. F. Ahmad, J. Avruch, and J. R. Woodgett. 1994. The stressactivated protein kinase subfamily of c-Jun kinases. Nature (London) 369:156-160.

45. Lee, T. H., L. Klampfer, T. B. Shows, and J. Vilcek. 1993. Transcriptional regulation of TSG6, a tumor necrosis factor- and interleukin-1-inducible primary response gene coding for a secreted hyaluronan-binding protein. J. Biol. Chem. 268:6154-6160.

46. Lenardo, M. J., and D. Baltimore. 1989. NF-kappa B: a pleiotropic mediator of inducible and tissue-specific gene control. Cell 58: 227-229.

47. Loetscher, H., D. Stueber, D. Banner, F. Mackay, and W. Lesslauer. 1993. Human tumor necrosis factor alpha (TNF-alpha) mutants with exclusive specificity for the $55-\mathrm{kDa}$ and $75-\mathrm{kDa}$ TNF receptors. J. Biol. Chem. 268:26350-26357.

48. Mathias, S., K. A. Dressler, and R. N. Kolesnick. 1991. Characterization of a ceramide-activated protein kinase: stimulation by tumor necrosis factor alpha. Proc. Natl. Acad. Sci. USA 88:10009-10013.

49. Mathias, S., A. Younes, C.-C. Kan, I. Orlow, C. Joseph, and R. N. Kolesnick. 1993. Activation of the sphingomyelin signaling pathway in intact EL4 cells and in a cell-free system by IL-1 $\beta$. Science 259:519-522.

50. Muegge, K., M. Vila, G. L. Gusella, T. Musso, P. Herrlich, B. Stein, and S. K. Durum. 1993. Interleukin-1 induction of the c-jun promoter. Proc. Natl. Acad. Sci. USA 90:7054-7058.

51. Muegge, K., T. M. Williams, J. Kant, M. Karin, R. Chiu, A. Schmidt, U. Siebenlist, H. A. Young, and S. K. Durum. 1989. Interleukin-1 costimulatory activity on the interleukin-2 promoter via AP-1. Science 246:249-251.

52. Mukaida, N., Y. Mahe, and K. Matsushima. 1990. Cooperative interaction of nuclear factor- $\mathrm{KB}$ and cis-regulatory enhancer binding protein-like factor binding elements in activating the interleukin-8 gene by pro-inflammatory cytokines. J. Biol. Chem. 265: 21128-21133.

53. Ostrowski, J., K. E. Meier, T. H. Stanton, L. L. Smith, and K. Bomsztyk. 1988. Interferon- $\gamma$ and interleukin- $1 \alpha$ induce transient translocation of protein kinase $\mathrm{C}$ activity to membranes in a $\mathrm{B}$ lymphoid cell line. J. Biol. Chem. 263:13786-13790.

54. Pulverer, B. J., J. M. Kyriakis, J. Avruch, E. Nikolakaki, and J. R. Woodgett. 1991. Phosphorylation of c-Jun mediated by MAP kinases. Nature (London) 353:670-674.

55. Qwarnstorm, E. E., S. A. MacFarlene, R. C. Page, and S. K. Dower. 1991. Interleukin $1 \beta$ induces rapid phosphorylation and redistribution of talin: a possible mechanism for modulation of fibroblast focal adhesion. Proc. Natl. Acad. Sci. USA 88:1232-1236.

56. Rachie, N. A., R. Seger, M. A. Valentine, J. Ostrowski, and K. Bomsztyk. 1993. Identification of an inducible $85 \mathrm{kDa}$ nuclear protein kinase. J. Biol. Chem. 268:22143-22149.

57. Raines, M. A., R. N. Kolesnick, and D. W. Golde. 1993. Sphingomyelinase and ceramide activate mitogen-activated protein kinase in myeloid HL-60 cells. J. Biol. Chem. 268:14572-14575.

58. Rangnekar, V. V., S. Waheed, and V. M. Rangnekar. 1992. Interleukin-1 inducible tumor growth arrest is characterized by activation of cell type-specific "early" gene expression programs. J. Biol. Chem. 267:6240-6248.

59. Ruddle, N. H., and B. H. Waksman. 1967. Cytotoxicity effect of lymphocyte-antigen interaction in delayed hypersensitivity. Science 157:1060-1062
60. Schlessinger, J. 1988. Signal transduction by allosteric receptor oligomerization. Trends Biochem. Sci. 13:443-447.

61. Schonthal, A., M. Buscher, P. Angel, H. J. Rahmsdorf, H. Ponta, K. Hattori, R. Chiu, M. Karin, and P. Herrlich. 1989. The Fos and Jun/AP-1 proteins are involved in the downregulation of Fos transcription. Oncogene 4:629-636.

62. Seth, A., F. A. Gonzalez, S. Gupta, D. L. Raden, and R. J. Davis. 1992. Signal transduction within the nucleus by mitogen-activated protein kinase. J. Biol. Chem. 267:24796-24804.

63. Shirakawa, F., M. Chedid, J. Suttles, B. A. Pollock, and S. B. Mizel. 1989. Interleukin 1 and cAMP induce kappa immunoglobulin ight chain expression via activation of an NF-kappa B-like DNA-binding protein. Mol. Cell. Biol. 9:959-964.

64. Shirakawa, F., U. Yamashita, M. Chedid, and S. B. Mizel. 1988. cAMP - an intracellular second messenger for interleukin-1. Proc. Natl. Acad. Sci. USA 85:8201-8205.

65. Smeal, T., B. Binetruy, D. Mercola, B. A. Grover, G. Heidecker, U. R. Rapp, and M. Karin. 1992. Oncoprotein-mediated signalling cascade stimulates c-Jun activity by phosphorylation of serines 63 and 73. Mol. Cell. Biol. 12:3507-3513.

66. Smeal, T., B. Binetruy, D. A. Mercola, M. Birrer, and M. Karin. 1991. Oncogenic and transcriptional cooperation with Ha-Ras requires phosphorylation of c-Jun on serines 63 and 73. Nature (London) 354:494-496.

67. Tamura, M., N. Arakaki, H. Tsubouchi, H. Takada, and Y. Daikuhara. 1993. Enhancement of human hepatocyte growth factor production by interleukin- $1 \alpha$ and-1 $\beta$ and tumor necrosis factor- $\alpha$ by fibroblasts in culture. J. Biol. Chem. 268:8140-8145.

68. Tartaglia, L. A., T. M. Ayres, G. H. W. Wong, and D. V. Goeddel. 1993. A novel domain within the $55 \mathrm{kDa}$ TNF receptor signals cell death. Cell 74:845-853.

69. Tartaglia, L. A., and D. V. Goeddel. 1992. Tumor necrosis factor receptor signaling: a dominant negative mutation suppresses the activation of the $55-\mathrm{kDa}$ tumor necrosis factor receptor. J. Biol. Chem. 267:4304-4307.

70. Tartaglia, L. A., and D. V. Goeddel. 1992. Two TNF receptors. Immunol. Today 13:151-153.

71. Tartaglia, L. A., D. Pennica, and D. V. Goeddel. 1993. Ligand passing: the $75-\mathrm{kDa}$ tumor necrosis factor (TNF) receptor recruits TNF for signaling by the $55-\mathrm{kDa}$ TNF receptor. J. Biol. Chem. 268:18542-18548.

72. Tartaglia, L. A., M. Rothe, Y.-F. Hu, and D. V. Goeddel. 1993. Tumor necrosis factor's cytotoxic activity is signaled by the p55 TNF receptor. Cell 73:213-216.

73. Tartaglia, L. A., R. F. Weber, I. S. Figari, C. Reynolds, M. A. Palladino, and D. V. Goeddel. 1991. The two different receptors for tumor necrosis factor mediate distinct cellular responses. Proc. Natl. Acad. Sci. USA 88:9292-9296.

74. Vietor, I., P. Schwenger, W. Li, J. Schlessinger, and J. Vilcek. 1993. Tumor necrosis factor-induced activation and increased tyrosine phosphorylation of mitogen-activated protein (MAP) kinase in human fibroblasts. J. Biol. Chem. 268:18994-18999.

75. Vojtek, A. B., S. M. Hollenberg, and J. A. Cooper. 1993. Mammalian Ras interacts directly with the serine/threonine kinase Raf. Cell 74:205-214.

76. Wiegmann, K., S. Schütze, E. Kampen, A. Himmler, T. Machleidt, and M. Krönke. 1992. Human 55-kDa receptor for tumor necrosis factor coupled to signal transduction cascades. J. Biol. Chem. 267:17997-18001.

77. Wong, G. H. W., L. A. Tartaglia, M. S. Lee, and D. V. Goeddel. 1992. Antiviral activity of tumor necrosis factor is signaled through the 55-kDa type 1 TNF receptor. J. Immunol. 149:3550-3553.

78. Zhang, Y., J.-X. Lin, and J. Vilcek. 1990. Interleukin-6 induction by tumor necrosis factor and interleukin-1 in human fibroblasts involves activation of a nuclear factor binding to a $\mathrm{\kappa B}$-like sequence. Mol. Cell. Biol. 10:3818-3823.

79. Zhang, Y., J. X. Lin, Y. K. Yip, and J. Vilcek. 1988. Enhancement of cyclic AMP levels and of protein kinase activity by tumor necrosis factor and interleukin-1 in human fibroblasts: role in the induction of interleukin 6. Proc. Natl. Acad. Sci. USA 85:68026805 . 